\title{
Al son del ritmo español: Música y canciones en el aula de ELE/EL2
}

\author{
Ana María AGUILAR LÓPEZ \\ Universidad de Burgos \\ Departamento de Didácticas Específicas (Área de Didáctica de la Lengua y la Literatura) \\ amaguilar@ubu.es
}

Recibido: marzo 2012

Aceptado: enero 2013

\begin{abstract}
RESUMEN
El siguiente artículo está formado por dos bloques: uno teórico y otro práctico. El hilo conductor de ambos es el uso de las canciones. En la parte teórica se analizan las posibilidades que ofrece la inclusión de canciones en el aula de idiomas, así mismo, puesto que no dejan de ser una muestra de lengua oral, se abordan cuestiones metodológicas relacionadas con la comprensión oral y se incluyen reflexiones sobre cómo este material puede mejorar dicha actividad de lengua. En la parte práctica se explicita una serie de actividades que explotan didácticamente las canciones elegidas y con las que, en último término, pretendemos trabajar los tiempos pasados de indicativo del español y la macrofunción de la narración.
\end{abstract}

Palabras clave: comprensión oral, canciones, tiempos del pasado, Nivel B1.2, Español Lengua Extranjera/Segunda Lengua.

\section{Au rythme espagnol: musique et chansons pour la classe de ELE/EL2}

\section{RÉSUMÉ}

L'article qui suit se compose de deux parties: l'une théorique et l'autre pratique. Le fil conducteur des deux est l'utilisation des chansons. Dans la partie théorique nous analysons les possibilités offertes par l'inclusion de chansons dans la classe de langue. De même, puisque les chansons sont toujours un échantillon du langage oral, des questions méthodologiques seront abordées liées à la compréhension à l'oral et nous essayerons, également, de réfléchir sur la façon dont cet outil pédagogique peut améliorer cette habileté du langage. Dans la partie pratique nous explicitons toute une série d'activités qui exploitent les chansons choisies de façon didactique et avec lesquelles, en fin de compte, nous avons l'intention de travailler l'indicatif au passé en espagnol et la macrofonction de la narration.

Mots-clé: compréhension à l'oral, chansons, temps au passé, Niveau B1.2, Espagnol Langue Étrangère / Deuxième Langue.

\section{Spanish rhythm: music and songs for SFL/SSL classes}

\begin{abstract}
The following article consists of two separate parts: one theoretical and one practical. The theme underlying both blocks is the use of songs. In the theoretical part, we analyse the possibilities brought about by the use of songs in the language classroom. Likewise, since
\end{abstract}


they are still a sample of oral language, we address methodological issues related to the aural skills and include reflections on how this material may enhance these very same skills. In the practical part, we explicit bring up a series of activities that exploit the songs chosen didactically and with which, in the end, we intend to work the past tense of Spanish verbs in the their indicative form and the macro function of the narrative ${ }^{1}$.

Keywords: aural skills, songs, past tenses, Level B1.2, Spanish as a Foreign Language / Second Language

SUMARIO: 0. Canciones en el aula de idiomas: pieza musical, producto cultural e input. 1. La comprensión oral como proceso: consideraciones a tener en cuenta. 2. Canciones para desarrollar la comprensión oral. 3. Propuesta didáctica: cinco canciones de amor y una historia desesperada. 3.1. Primera fase: introducción del tema. 3.2. Segunda fase: trabajamos con las canciones. 3.2.1. Actividades para la canción Mediterráneo. 3.2.2. Actividades para trabajar la canción de Eva María. 3.2.3. Actividad para trabajar las canciones Vacaciones de verano y Amor de verano. 3.2.4. Actividad para trabajar la canción $U n$ rayo de sol.3.3. Tercera fase: historias musicales. 3.3.1.Primera parte: comprensión escrita y gramática. 3.3.2.. Segunda parte: expresión escrita. 4. Conclusiones. 5. Bibliografía.

\section{CANCIONES EN EL AULA DE IDIOMAS: PIEZA MUSICAL, PRODUCTO CULTURAL E INPUT}

Varios son los motivos que pueden justificar la presencia de una canción en el aula de idiomas. En principio parece evidente que las canciones sirven para ser escuchadas y cantadas, aunque en el aula de idiomas, no es muy habitual que el docente tenga exclusivamente estos objetivos. Tim Murphey $(2010,6)$ señala que las canciones pueden ser un material muy valioso dentro del aula de idiomas, puesto que a través de ellas podemos hacer que los estudiantes desarrollen ciertas capacidades, si bien, este autor considera que las canciones son, si cabe, más valiosas aún, si el docente las explota de forma creativa para construir un puente entre la experiencia placentera que supone escucharlas o cantarlas y el uso comunicativo de la lengua.

La mayoría de las veces que los docentes de idiomas incorporan una canción en su aula, tratan de conectarla con objetivos didácticos, lo que les conduce a poder explotar la canción desde diferentes puntos de vista. Así, es posible que el docente introduzca en sus clases piezas musicales como estímulo a partir del cual arranque una actividad o para ponerlas de fondo, provocar ciertas sensaciones y contribuir con esto a generar un determinado clima en el aula que le es conveniente para el desarrollo de una actividad, etc. En este sentido se pronuncia Lucía I. Llorente $(2009,70)$ quien manifiesta que, al dar cabida en el aula de idiomas a las

\footnotetext{
${ }^{1}$ Queremos mostrar nuestro más sincero agradecimiento al traductor D. Ismael Sáiz Herrera por su colaboración en la traducción al inglés y al francés del resumen y de las palabras clave de este artículo.
} 
canciones, no hacemos sino favorecer la reducción de la ansiedad y propiciar la relajación (suponemos que aquéllas que tengan una melodía más pausada) ${ }^{2}$.

Más usual suele ser que al docente le interese explotar la canción como un producto cultural y, desde ese punto de vista, es posibe que quiera incidir en los ritmos propios de ciertas zonas geográficas o en el género musical al que pertenecen una serie de canciones, en los usos que se dan a ciertas melodías (nanas, canciones de cumpleaños...), también, dado que muchas canciones van asociadas a festividades (villancicos, fiestas locales, etc.) el docente puede querer proporcionar información cultural sobre las propias celebraciones, vestimentas, danzas, ritos asociados a ellas, etc. Así mismo puede ser que le interese trabajar la discografía de ciertos cantantes o grupos, que desee presentar a los estudiantes grupos ignotos por ellos o canciones y estilos representativos de ciertas épocas, etc. Como vemos, a la hora de plantearnos trabajar la música como un producto cultural, las opciones para hacerlo son muy variadas.

No es extraño encontrar canciones en el apartado de cultura de las unidades de muchos métodos de español, como tampoco lo es que, dentro de la clase de idiomas, se trabajen las canciones como texto oral y escrito que sirve de aducto o input para los alumnos. Desde esta perspectiva, el docente puede plantear actividades que evalúen la comprensión que tiene el alumnado de las canciones, actividades sobre el tema de la canción, su mensaje y las funciones comunicativas a las que se recurren para transmitirlo o sobre la forma en la que la canción elegida lo hace (registros, estructuras gramaticales, léxico, rasgos discursivos, tipología textual, recursos estilísticos, etc.). Consideramos, por lo visto hasta aquí, que no existe un único criterio de selección que justifique la presencia de canciones en el aula de español, sino más bien unas necesidades docentes que poder abordar con este material.

De lo que no cabe duda es de que la incorporación de las canciones en el aula ha de quedar justificada de algún modo. Cuando el docente decide incluir una canción como producto cultural pero, sobre todo, como muestra de la lengua meta, es preciso que la canción seleccionada esté conectada o relacionada con alguno de los contenidos previamente programados o tratados en la unidad al hilo de la cual quiere incluirla. Parece, pues, claro que al profesorado le corresponde la elección del material sonoro, pues nadie como él para conocer los pormenores de su

\footnotetext{
2 Además, esta misma autora $(2009,70)$ también menciona como efectos positivos del uso de las canciones en el aula una mayor predisposición al aprendizaje y un aumento de la participación emocional en el proceso de aprendizaje, aspectos todos estos que se relacionan con la hipótesis del filtro afectivo de Krashen. Así mismo, otros autores como Jiménez, Martín y Puigdevall $(2009,132)$ amplían el campo al señalar la influencia de las canciones en la formación del individuo y destacan su empleo como elemento de integración de las personas en grupos sociales, de armonía con uno mismo y con el grupo, cultura, patria, religión, revolución etc.
} 
programación. En opinión de Miriam Ballesteros $(2010,126)$ las canciones que se lleven al aula de idiomas han de cumplir una serie de requistitos, que son: que el texto de la canción sea claro, corto, con palabras de fácil comprensión y pronunciación, que tenga un contenido literario atractivo y con una carga semántica adecuada al nivel de adquisición del alumnado. A nuestro entender, si no todos, la mayoría de estos requisitos pueden resultar referentes de cierta importacia si pretendemos abordar las canciones como texto, pero, consideramos que no son tan necesarios si el docente pretende explotarlas como piezas musicales o culturales.

Por otro lado, también cabe la opción de que los alumnos propongan canciones al docente. La razón de mayor peso para que éste les escuche y recoja sus propuestas está relacionada con la motivación. El hecho de que la música constituya un material habitual fuera del aula, inherente a nuestra existencia, por cuanto está presente en multitud de escenarios cotidianos (el coche, las tiendas, la casa...) y al que recurrimos en nuestro tiempo de distensión o de ocio, hace que adquiera una connotación especial y que la sola idea de incluirla en el aula provoque un incremento motivacional en el alumnado de idiomas.

Dicha motivación, además, está en no pocos casos reforzada por el propio contenido de las canciones, ya que éstas tratan temas y sentimientos universales, contribuyen a generalizar situaciones y pueden por esto conectar con las experiencias vitales de personas de cualquier parte del mundo. En tanto en cuanto esto sea así, es de esperar que la motivación de los estudiantes hacia las actividades que se relacionan con una determinada canción que les ha llegado a "calar" de este modo, aumente. $\mathrm{Si}$, como afirman algunos autores ${ }^{3}$, la motivación es uno de los factores más influyentes en la Adquisición de Segundas Lenguas (L2) o Lenguas Extranjeras (LE), es necesario que el docente escuche las opiniones de sus alumnos respecto a este tema y las atienda en la medida de lo posible, puesto que no siempre es factible trabajar las canciones como los alumnos esperan que se haga y es que, por lo general, cuando los alumnos proponen canciones al profesorado, quieren saber qué significan, lo que implica trabajarlas como aducto o input. En no pocas ocasiones sucede que las canciones propuestas, a pesar de la melodía pegadiza o de su difusión, tienen un texto demasiado alejado del nivel de lengua del que parten los alumnos ${ }^{4}$. En tales casos el profesor ha de sopesar muy bien si incluir dichas

${ }^{3}$ Por ejemplo para Isabel Santos Gargallo $(1999,25)$ la motivación es "si no el factor más importante, uno de los más determinantes para lograr el éxito en el aprendizaje de una segunda lengua o lengua extranjera”. En opinión de Marta Baralo $(1999,31)$ la motivación "determina que se produzca realmente una apropiación del conocimiento o que ese conocimiento no se arraigue”.

${ }^{4} \mathrm{Al}$ proferir esta idea estamos teniendo presente la hipótesis del input de Krashen, según la cual el papel del aducto o input es fundamental en la adquisición de una lengua, pero no todos los tipos de aducto aportan beneficios al aprendiz. Así, si el aducto no se comprende, éste equivale a ruido, con lo cual no ayuda a progresar en el desarrollo de la lengua. Si es 
canciones en el aula puede volverse en su contra, pues, pese a la motivación inicial que los alumnos puedan tener ante la idea de hacerlo, puede ser que el trabajo que requiere la comprensión de las mismas sea tal, que llegue a cansar a los discentes, ¿qué puede hacer entonces el docente? puede optar por trabajar las canciones en cuestión como contenido cultural, como pieza musical o bien, si es que persiste en la idea de trabajar la canción como input, plantearse la posibilidad de una comprensión más superficial, centrándose en algunas partes, en la identificación del tema, etc.

A veces también sucede que las propuestas del alumnado se apartan de los contenidos trabajados en el aula, de ser así el profesor puede optar por anotarlas para llevarlas a clase llegado el momento oportuno.

Además, si quienes eligen las canciones son los alumnos, debemos partir de la presunción de que el abanico de estilos y ritmos entre el cual pueden elegir es tan amplio, que cada discente seguramente encuentre unas cuantas canciones en la lengua meta de su agrado. Relacionado precisamente con los gustos personales, puede surgir otro problema y es que los estudiantes de un mismo grupo tengan preferencias totalmente dispares e incluso una cierta adversión a estilos opuestos. Ante tal situación, el docente ha de intentar ofrecer estilos variados de forma que todos los alumnos puedan sentir que sus gustos están representados en el aula. Además de esto, Beatriz Rodríguez López $(2005,808)$ aconseja que el docente mantenga un buen clima socio relacional en el aula y que fomente entre los alumnos la tolerancia y el respeto por los gustos ajenos y opuestos a los propios.

En conclusión, es al docente a quien en último término le compete tomar la decisión de incorporar o no una determinada canción en el aula; incluso cuando la propuesta parta de los propios alumnos, es él quien debe dar el visto bueno final. Una vez que el docente tenga claros los objetivos que le han conducido a incorporar una determinada canción al aula, y especialmente si decide incluirla como pieza cultural o como muestra de la lengua meta, ha de planificar una secuenciación didáctica que le permita poder alcanzar dichos objetivos.

\section{LA COMPRENSIÓN ORAL COMO PROCESO: CONSIDERACIONES A TENER EN CUENTA}

Para trabajar el aducto oral en general y en concreto las canciones como texto oral, proponemos abordar la comprensión oral en los tres momentos clásicos de actuación pedagógica: antes, durante y después de la audición, es decir, contemplar

tan sumamente sencillo que el sujeto no tiene que hacer ningún esfuerzo por comprender, tampoco reportará beneficios a la competencia comunicativa. Sólo el aducto que supera levemente el nivel del aprendiz puede mejorar su educto o output. El aprendiz puede comprender ese aducto infiriendo información del contexto lingüístico y situacional, así como de los conocimientos acumulados sobre el mundo y la lengua, de los gestos, de las explicaciones, las imágenes, etcétera. 
la actividad de la comprensión oral como un proceso y no como un producto. Cuando reducimos la evaluación de la comprensión oral a la corrección de unas preguntas finales propuestas al hilo de la audición (después de la escucha), no hacemos sino plantear la comprensión oral como un producto.

Antes de la audición, es habitual que el docente, contextualice o enmarque la audición que va poner en el aula, que active o proporcione conocimiento relevante sobre el tema de la audición y sobre la lengua. Así, al preparar la explotación didáctica de las muestras de lengua orales que pretende llevar al aula, el profesorado se suele plantear qué tipo de información (léxico, relaciones semánticas, conocimientos culturales o de otra índole, etc.) merece la pena exteriorizar y, en su caso trabajar, antes de la exposición al texto oral, cara a tener ciertas garantías de que los alumnos van a poder realizar, al menos de manera aceptable, la tarea que se les pide al hilo de una audición dada. Al hacerlo así, el profesorado favorece la comprensión de todos y no sólo de aquéllos que tengan la información necesaria para hacerlo de ante mano. Así mismo, es común que el docente, además de sus propios objetivos didácticos, plantee a los alumnos objetivos de escuha que contribuyan a que se impliquen más en la actividad y, por tanto, aumenten su motivación e interés en hacerla.

Cuando el docente define estos objetivos de escucha ayuda a los estudiantes a escuchar de forma selectiva en busca de información significativa, lo cual es más fácil y más real también que intentar comprender todo (Ur, 1997, 108). El docente ha de variar los objetivos de escucha que propone a los discentes, pues, en gran medida, de ellos va a depender que los estudiantes se queden con una información u otra o lo que es lo mismo, de ellos va a depender que los estudiantes hagan una escucha más superficial o más profunda. Sin embargo, pese a todo lo dicho, Goodith White $(2003,6)$ es de la opinión de que con este tipo de prácticas (enseñanza de vocabulario antes de la escucha, establecimiento de objetivos previos a la audición, etc.) imponemos a los alumnos una docencia coercitiva que no les deja mucho margen para que desarrollen estrategias de comprensión. ¿Significa ello que debemos evitarlas? Consideramos que la cuestión no está en si es pertinente evitarlas o no, sino, más bien, en no hacer de este modo de proceder la única forma de abordar la comprensión oral antes de la audición. Es decir, ésta puede ser una práctica tan buena como cualesquiera otras, pero debemos ser conscientes de que no es la única y por tanto hacer un esfuerzo por variarla, de ahí que, por ejemplo, a veces el docente quiera, por qué no, que el alumno, de forma puntual, se enfrente a la audición sin ningún tipo de consigna previa bien para que recurra a conocimientos previos, bien para entrenarlo en una escucha más semejante a las de la vida real o bien por simple diversión. Por otro lado, al igual que sucede con la comprensión escrita (lectura), existe una exposición al material auditivo cuyo único objetivo es meramente hedonista, se puede disfrutar escuchando una canción, asistiendo a una sesión de cuentacuentos o viendo una película, y no siempre se tiene que plantear, si no se quiere, un objetivo que vaya 
más allá del propio disfrute, pues este disfrute coincide con uno de los objetivos más frecuentes en las situaciones de escucha de la vida real.

En el caso de las canciones, pero también de otros materiales auditivos, el docente puede partir del título de la canción, de otras fuentes que se puedan relacionar con ésta como vídeos o fotos, de unas preguntas que inciten a la discusión, de una lluvia de ideas, antes de la audición el docente también puede dar opciones a los alumnos de que exterioricen conocimientos previos, puede intentar conectar las ideas principales del texto oral con los conocimientos previos de los alumnos sobre ese tema, etc.

Durante la audición se ha de producir la comprensión. Cabe la posibilidad de que el docente no quiera plantear ninguna actividad que pueda distraer la atención de los discentes, pero también es posible que opte por enseñar o entrenar a sus alumnos en la práctica de ciertas estrategias de comprensión, para ello es preciso que interrumpa el proceso de la escucha e inste a los dicentes a que formulen predicciones sobre lo que va a suceder, que les pida que hagan inferencias cuando las claves de los significados más desconocidos pueden estar en el texto (contexto lingüístico) o en sus conocimientos previos, etc. Además, sería deseable que, para trabajar la estrategia del autocontrol, el docente incluyera al alumno en interacciones reales en las que éste pudiera hacer también de interlocutor y solicitar aclaraciones en caso de que lo considerara necesario.

Otra opción a considerar por el docente durante la audición es la de guiar la comprensión y la interpretación planteando cuestiones sobre las cuales focalizar su atención y al hilo de las cuales los estudiantes tomen notas. Para Penny Ur (1997, 108) es aconsejable brindar a los estudiantes la oportunidad de que respondan de manera intermitente durante la escucha, es decir, que tengan la opción de ir respondiendo a lo que se les pide a medida que van escuchando sin tener que esperar al final de la audición para empezar a responder, pues en tal caso, la comprensión puede confundirse con un acto de memorización.

El riesgo que el docente puede correr al plantear respuestas intermitentes durante la audición es el de saturar al alumnado hasta tal punto de parecer que le está pidiendo una transcripción de lo que oye. En efecto, si pedimos muchas respuestas a los estudiantes durante la audición y ésta no es lo suficientemente redundante, puede que los estudiantes no tengan el tiempo suficiente para tomar sus notas durante la escucha, lo que en última instancia puede generar frustración, fatiga e irritación en el alumnado y con razón, pues la realización de esta actividad no tendría que ver tanto con la comprensión oral, sino, más bien, con la rapidez de escritura. Pese a todo, como Ur señala (Ibíd. 112), este tipo de escucha es fomentado en ocasiones tanto por el profesorado como por los libros de texto u otros materiales.

Éste es un reto que no beneficia el desarrollo de una comprensión oral eficaz, puesto que damos a entender a los alumnos que todas las palabras de la audición tienen la misma importancia, con lo cual los estudiantes orientarán sus esfuerzos a 
intentar "captar" todas y cada una de ellas. Por si esto fuera poco, esta práctica se relaciona con uno de los problemas más comunes que, según Penny Ur (Ibíd. 111), tienen quienes aprenden una LE/L2 que es el de querer entender todo lo proferido en dicha lengua, cuando no se consigue el alumno se siente frustrado y estresado.

Puede ser, sin embargo, que, de forma puntual, el docente quiera que los discentes hagan una transcripción de un texto, pero ha se ser con una finalidad que justifique tal actividad y sin abusar de esta práctica. En tal caso, aconsejamos que se opte por un texto que no sea muy extenso ni esté muy alejado del nivel de adquisición de la lengua meta que manejan los discentes 5 , así mismo creemos conveniente que los alumnos puedan tener el poder de parar la audición y retroceder cuantas veces quieran. Pese a todo, es preferible destinar la mayor parte del tiempo que pretendemos dedicar a trabajar la comprensión oral a acostumbrar a nuestros alumnos a que sean selectivos, a que aprendan a identificar la información importante y se centren en ella desdeñando la secundaria, por ejemplo, podemos ponerles de forma ocasional audiciones extensas de las que tengan que quedarse con dos o tres datos. Entre las actividades más habituales para trabajar la comprensión oral en este momento, durante la audición, están por ejemplo: ordenar viñetas, estrofas o ideas, completar partes del texto, detectar errores del texto que se les facilita previamente, identificar, etc.

A la hora de hablar del trabajo que puede hacer el docente tras una audición debemos diferenciar dos aspectos: el uso de la audición como texto y el uso de la audición como pretexto. Como texto oral que es, debemos comprobar el grado de comprensión que los discentes han tenido de la audición y si han cumplido el objetivo con el cual se ha planteado su escucha. Como pretexto, y de forma opcional, el docente puede incluir después de una audición otro tipo de actividades que no tienen que ver directamente con su comprensión pero se relacionan con ésta a través de la temática, de algún aspecto gramatical, etc.

Cuando se evalúa la comprensión de la audición, normalmente se plantean actividades de verdadero o falso, de corregir información que se considere errónea, de contestar a algunas preguntas, realización de esquemas o de dibujos que demuestren la comprensión, la elección de un título que pueda aglutinar la idea principal, etc. Haciéndonos eco de las palabras de G. White $(2003,5)$, debemos llamar la atención sobre el hecho de que normalmente los docentes no destinamos mucho tiempo a identificar qué es lo que ha fallado, es decir, qué problemas han tenido los estudiantes, por qué se han perdido, no han entendido o no han respondido bien. El docente debe ser flexible ante las respuestas que den los discentes a las preguntas planteadas $y$, en caso de error, indagar en los motivos que

\footnotetext{
${ }^{5}$ A la hora de hacer esta última recomendación, estamos teniendo presente una vez más la teoría del input de Krashen.
} 
les han conducido a responder de la forma en la que lo han hecho, pues puede ocurrir que, ante una misma pregunta, más de una respuesta sea válida.

Además de estas actividades, como decimos, el docente puede aprovechar la audición para hacer actividades de expansión que, de algún modo, se conecten con la audición que se ha escuchado. Entre las actividades más comunes que se suelen realizar durante esta estapa están por ejemplo versionar lo que se ha escuchado, cambiar la tipología textual de la audición, realizar debates sobre alguna de las ideas de la audición que puedan resultar más polémicas, etc.

\section{CANCIONES PARA DESARROLLAR LA COMPRENSIÓN ORAL}

Entre las preocupaciones que la comprensión oral suscita en los alumnos de idiomas, están por ejemplo la velocidad de elocución, la inseguridad respecto a si lo que se está entendiendo es realmente lo que se dice o el miedo a que una audición más extensa pueda hacer que desistan de querer comprender lo que se dice en ella. Al objeto de paliar los efectos generados por estos problemas y, en última instancia, de garantizar una mayor comprensión oral, los discentes suelen hacer una serie de peticiones al profesorado a las que no siempre debe ceder.

Así, ante las reiteradas demandas por parte de los estudiantes de que empleemos un ritmo de elocución más lento a la hora de hablar con ellos en la lengua meta, Penny Ur advierte de que si cedemos, no expondremos a los estudiantes a la lengua real, lo que en última instancia significa que no les ayudaremos a que se enfrenten a la forma natural en la que los hablantes nativos se comunican. Lo adecuado sería, según Ur $(1997,112)$ que los expusiéramos cuanto antes mejor, a un lenguaje espontáneo y natural, (tampoco excesivamente rápido). Además, sería positivo que el docente incluyera diferentes acentos, incluso desde los niveles inferiores, puesto que ello no convertiría el acento en un obstáculo para la comunicación, antes bien, incrementaría las posibilidades de comunicación entre los discentes y los nativos.

Otra de las peticiones que podemos escuchar de nuestros alumnos es que repitamos la información más de una vez para asegurarse de que comprenden. A este respecto Ur (Ibíd.) aconseja que incluyamos entre las audiciones textos redundantes, en los que la información importante se repita más de una vez pero, a ser posible, con reformulaciones, es decir, expresándola de diversas formas. Así mismo, este autor observa que algunos estudiantes parecen preferir audiciones breves, pues, de lo contrario, pierden la concentración y el interés.

Pensamos que las canciones pueden ser un material muy útil para complacer estas peticiones del alumnado a través de muestras de lengua reales, puesto que su ritmo abarca desde el lento al rápido, algunos autores como María del Prado (2004, 43), consideran que, dado que en las canciones el texto se acomoda a la música y al 
ritmo, cantarlas obliga a los discentes a una dicción más rápida ${ }^{6}$, lo que en último término repercute en una mayor fluidez de expresión oral; si bien nosotros suponemos que esto, de ser así, sólo sucederá con canciones que tengan un ritmo rápido. Además a través de las canciones se manifiestan los diferentes acentos del mundo hispánico, su contenido suele ser bastante repetitivo, aunque no siempre se haga a través de reformulaciones, y a menudo su música es pegadiza ${ }^{7}$, lo que contribuye a la memorización de estructuras de la lengua objeto. A pesar de su lacónica duración, pueden llegar a condensar verdaderas historias, por lo que no llegan a cansar a aquéllos alumnos que pierden la atención ante audiciones extensas.

Por otro lado las canciones permiten introducir en el aula algunos de los aspectos relacionados con las situaciones reales de escucha que no están presentes normalmente en las audiciones de los CDs o cintas de los métodos que se llevan al aula, tales como la visibilidad del emisor (cantante) a través de un vídeoclip, por ejemplo, que nos pueda dar información sobre el contexto comunicativo en el que se enmarca su letra, aunque, una vez más, somos conscientes de que tampoco todos los viodeoclips contribuyen a marcar un contexto comunicativo. Así mismo, mediante la inclusión de las canciones en el aula de ELE/EL2 queda justificada la repetición de la audición, ya que no es extraño que los propios nativos repitan la escucha de canciones por el mero placer de volverlas a escuchar, es decir, la repetición del mensaje se corresponde con una práctica que funciona en la vida real, por lo que queda menos forzada en el aula.

Hemos referido aquí algunas de las ventajas derivadas de la inclusión de las canciones en el aula de idiomas, si bien, por la propia estructura del trabajo que presentamos las hemos vinculado de manera especial a la comprensión oral. Aunque lo cierto es que a través de las canciones podemos trabajar todas las actividades de la lengua objeto (comprensión oral y escrita, expresión oral y escrita, interacción y mediación).

Pese a todo, estamos de acuerdo con Tim Murphey $(20010,6)$ quien comenta: "Songs alone, however, will not teach anyone how to use language. (...) Just

\footnotetext{
${ }^{6}$ Para Murphey $(2010,7)$ no deja de ser sorprendente que parezca más sencillo cantar que hablar en la lengua meta. En nuestra humilde opinión, hablar implica una mayor complejidad, ya que el hablante ha de generar el contenido, estructurarlo y expresarlo buscando las palabras que realmente se ajusten a lo que desea transmitir y hacerlo de acuerdo a unas reglas gramaticales, pragmáticas y sociolingüísticas previas y comunes a la comunidad de hablantes en la que se inserta en mensaje y todo ello de manera casi simultánea. En cambio, la actividad de cantar sustituye estos pasos por la repetición.

${ }^{7}$ Como Murphey comenta $(2010,6)$ es curioso comprobar cómo somos capaces de olvidar casi todo lo que hemos aprendido en otra lengua excepto las canciones que aprendimos en ella, por diversas razones permanecen en nuestra mente llegando a ser parte de nosotros.
} 
listening to and singing songs will not make students able to communicate in another language".

\section{PROPUESTA DIDÁCTICA: CINCO CANCIONES DE AMOR Y UNA HISTORIA DESESPERADA}

La siguiente secuenciación de actividades tiene lugar en el marco de Cursos internacionales de la Universidad de Burgos (España), es decir, en un contexto de inmersión lingüística. Dichas actividades se implementan en verano de 2012 con un grupo de 10 alumnos procedentes de la Universidad de Michigan. Todos ellos comparten la misma lengua materna: el inglés, y asisten a un curso intensivo de Español Segunda Lengua (EL2) de 60 horas impartidas en horario matutino y, excepcionalmente, vespertino de lunes a viernes entre el 14 de agosto y el 21 de septiembre. El nivel del curso ofertado es B1.2., según el Marco Común Europeo de Referencia para las lenguas, si bien, el nivel alcanzado en el dominio de la lengua meta, el español, por el alumnado no es homogéneo y existen bastantes y acusadas diferencias internas de adquisición en el grupo.

El manual por el que hemos optado para trabajar con este grupo es Aula 4. En el momento de implementar las actividades que aquí desarrollamos, nos encontramos hacia en el penúltimo bloque de la Unidad 2: El turista accidental, que se concibe con el objetivo general de contar anécdotas reales o inventadas, para lo cual la unidad pretende que los alumnos aprendan a narrar acontecimientos pasados, a hablar de causas y consecuencias (como, porque, así que...), que aprendan recursos para narrar anécdotas y para mostrar interés al escuchar una anécdota, así como aprender la forma y el uso del Pretérito Pluscuamperfecto de Indicativo y profundizar en el contraste entre el Pretérito Imperfecto y el Pretérito Indefinido del mismo modo.

Dado que en anteriores ocasiones el grupo ha manifestado su interés por las canciones y la música españolas y ha pedido a la profesora hacer actividades con este material, se diseña a petición del alumnado la secuenciación didáctica que se incluye en este artículo y que incide en los contenidos y objetivos propios de la unidad que se está viendo en el libro de clase, es por esto por lo que nos planteamos trabajar las canciones especialmente como una muestra de lengua oral, más que como meras piezas musicales o como producto cultural.

La secuenciación que aquí presentamos se basa en la explotación didáctica de canciones y en la creación final de un relato o narración. Se realizó durante tres sesiones seguidas de 50 minutos, además, parte de la actividad final, la que se corresponde con escribir una historia en pasado, se hizo de tarea para casa, los alumnos pudieron leer sus escritos ante la clase transcurridos unos días, el tiempo estimado para esta lectura depende de la cantidad de textos que haya en el aula, en nuestro caso se aproximó a los 50 minutos.

La secuenciación didáctica que llevamos acabo comprende tres fases: la primera de ellas se corresponde con una lluvia de ideas, que brinda la oportunidad de 
exteriorizar los conocimientos previos que los discentes puedan tener, que permite la introducción del tema y en la que se trabajan ciertos conocimientos socioculturales. La segunda fase se destina a un primer contacto con la letra (significado) y la melodía de las canciones. Incluye actividades que permiten trabajar especialmente la comprensión oral y escrita. Un esquema general de esta parte es el siguiente:

I.Actividades con la canción Mediterráneo del grupo Los Rebeldes.

II. Actividades con la canción Eva María de Fórmula V.

III. Actividades con las canciones Amor de verano del Dúo Dinámico y Vacaciones de verano de Fórmula $\mathrm{V}$.

IV. Actividades con la canción Un rayo de sol del grupo Los diablos.

La tercera fase a su vez está formada por dos partes:

a) La primera trabaja la competencia gramatical (pasados) y la actividad comunicativa de la comprensión lectora.

b) La segunda está destinada a la creación de una historia escrita. Su posterior lectura ante la clase y su evaluación de su comprensión.

\subsection{Primera fase: introducción del tema}

La sesión comienza con una lluvia de ideas en gran grupo. Se trata de que el alumnado, sirviéndose de sus experiencias, percepciones individuales y conocimientos previos, exteriorice ciertos contenidos que puedan resultarle útiles para el posterior desarrollo de las actividades y que le permitan evocar el ambiente veraniego del que se habla en éstas.

Para ello se proyecta en la pizarra la primera diapositiva del power point que incluye el diagrama de la Tabla1 y se les pide a los estudiantes que individualmente piensen en qué significa para ellos el verano o qué les sugiere esta estación y que anoten algunas de sus ideas de manera esquemática.

Tras dejar un par de minutos para que generen el contenido y, en caso de que lo necesiten, puedan buscar en el diccionario lo que quieren decir, los alumnos aportan sus ideas.

A medida que van respondiendo, la profesora escribe las respuestas hasta completar el esquema proyectado en una pizarra blanca. 
TABLA 1. Diagrama utilizado para la lluvia de ideas.

¿QUÉ SIGNIFICA PARA TI EL VERANO?

La profesora presenta el concepto de canción de verano y les pregunta si existe también en su país de origen. Al hilo de ello informa a los estudiantes de que las canciones con las que se va a trabajar son canciones del verano de décadas pasadas, a saber: Mediterráneo del grupo Los Rebeldes (1988), Vacaciones de Verano (1972) y Eva María (1973) del grupo Fórmula V, Amor de verano (1963) del Dúo dinámico y Un rayo de sol (1970) del grupo Los diablos.

\subsection{Segunda fase: trabajamos con las canciones}

Una vez que hemos introducido el tema, pasamos a la segunda fase del trabajo destinada a realizar una serie de actividades que permitan a los discentes tener un primer contacto con las canciones seleccionadas.

\subsubsection{Actividades para la canción Mediterráneo}

Comenzamos trabajando la canción Mediterráneo de Los Rebeldes. Pedimos a los alumnos que se organicen en parejas, a cada una les entregamos un juego de las unidades léxicas que figuran en la Tabla 2 (pero sin clasificar), lo que en nuestro caso supone cinco juegos. Para prepararlos diseñamos en el ordenador cada unidad léxica con tipografías y tamaños diferentes, después las imprimimos en folios de colores y las recortamos una a una. Cuando cada pareja tiene sus unidades léxicas, se les pide que las lean al objeto de aclarar posibles dudas. A continuación la profesora les informa de que va a proyectar el vídeo de una canción sin volumen, dicha canción incluye en su letra 13 de las 19 unidades léxicas que se les han facilitado. Cada pareja, teniendo como único elemento al que asirse las imágenes del vídeo, ha de clasificar las unidades léxicas en dos columnas: la de las que creen que aparecen en la canción y la columna de las que no aparecen en la canción. Es 
decir, la respuesta correcta coincidiría con la clasificación de la Tabla 2. Una vez que lo han hecho, les pedimos que reserven su propuesta para corregirla después.

No pretendemos que acierten la ubicación de todas las unidades léxicas, y esto lo dejamos bien claro antes de comenzar la actividad, sino, más bien, comprobar cuántas aciertan. En última instancia se trata de que se familiaricen con algunas de las palabras que aparecen en la canción, es decir, la idea es facilitar al alumnado un primer contacto con el contenido de la canción, al hacerlo de esta forma, los estudiantes tienen opción de consultar el diccionario en caso de que no comprendan alguna de estas unidades léxicas y, por ende, estar preparados para identificar mejor las palabras en el momento de la audición de la canción. Así mismo, acostumbramos a los alumnos a fijarse en el contexto y a que lo valoren como fuente de información que nos puede hacer predecir un contenido u otro.

TABLA 2. Juego de palabras que recortamos y que entregamos a cada pareja de alumnos

\begin{tabular}{|l|l|}
\hline \multicolumn{3}{|c|}{ PARA ESCUCHAR E IDENTIFICAR } \\
\hline SÍ APARECEN EN LA CANCIÓN & NO APARECEN EN LA CANCIÓN \\
\hline 1 Agobio de verano, 2 cuerpo & 1 infierno, 2 desilusión, 3 Sevilla, 4 \\
empapado en sudor, 3 cambiar & cambiar mar por asfalto, 5 (ciudad en \\
asfalto por mar, 4 (ciudad en verano) & verano) perfección sin \\
una jaula, 5 viajar, 6 sol, 7 & aglomeraciones, 6 dios de las nubes. \\
sensaciones, 8 paraíso, 9 nadar, 10 & \\
rincón, 11 soñar, 12 agobio, 13 dios & \\
del mar & \\
\hline
\end{tabular}

Seguidamente les mostramos la segunda diapositiva de nuestro power point que se corresponde con una fotografía de una playa del Mediterráneo abarrotada de gente $^{8}$, pedimos a los discentes que, individualmente, escriban tres frases para describir ese lugar y tres palabras que se correspondan con las sensaciones que les provoca una playa así de concurrida.

Después, en gran grupo, preguntamos a los alumnos si saben en qué mes se ha podido sacar la fotografía, cuál es el mes de vacaciones por excelencia para los españoles, si en su país existe un mes tradicionalmente asociado a las vacaciones estivales y a qué zona de España creen que puede pertenecer la fotografía. Al hilo de ello hablamos de que la fotografía se ha podido sacar en los meses de verano e incluso en las vacaciones de Semana Santa, hablamos también de agosto como mes tradicionalmente asociado a las vacaciones, de que el concepto de vacaciones no ha

\footnotetext{
${ }^{8}$ Para buscar fotografías de este tipo es suficiente con introducir en un buscador los términos: playa agoto y Mediterráneo o el nombre de alguna localidad famosa de esta zona.
} 
existido siempre en España, de que es habitual encontrar en las playas chiringuitos con bebida y comida tradicional como sangría, claras, cerveza con limón, paella, calamares, mariscos o espetos de sardinas. Se aclara que la fotografía pertenece al Mar Mediterráneo, que baña el este de España y que las playas del Mediterráneo son uno de los destinos preferidos por los españoles y muchos extranjeros.

A continuación les decimos que van a escuchar una canción que habla precisamente sobre la vida veraniega en el Mediterráneo y cuyo vídeo acaban de ver sin audio. En la primera escucha, manteniendo las parejas anteriores, han de comprobar si las unidades léxicas (Tabla 2) que habían asociado al vídeo de la canción sin audio eran correctas y, en caso de error, reubicarlas. Tras hacer la corrección en gran grupo, proyectamos la tercera diapositiva de nuestro power point, que se corresponde con la Tabla 3. Leemos su contenido para asegurarnos de que no existen dudas respecto a su significado y les planteamos una segunda escucha para que contesten individualmente a la pregunta que se les plantea en la Tabla $3^{9}$ :

TABLA 3. Ficha para evaluar la comprensión oral de la canción Mediterráneo

\section{ESCUCHA Y ELIGE}

¿Cuál de las siguientes ideas crees que se relaciona mejor con la canción que has escuchado?

1. La canción está hecha para las personas que viven en el Mediterráneo.

2. La canción está hecha para que las personas que viven lejos del Mediterráneo lo visiten, hace publicidad de esa zona.

3. La canción está hablando de los inconvenientes que tiene el verano en el Mediterráneo.

Pasamos seguidamente a profundizar en el contenido de la canción y proyectamos la cuarta diapositiva del power point en la que aparece la Tabla 4. Una vez que nos aseguramos de que comprenden lo que dice, hacemos en gran grupo la actividad.

TABLA 4. Ficha para trabajar la letra de la canción Mediterráneo

\begin{tabular}{|c|}
\hline \multicolumn{1}{|c|}{ LEE Y COMPARA } \\
\hline $\begin{array}{c}\text { Para describir la vida veraniega de la zona del Mediterráneo la letra de la } \\
\text { canción dice: }\end{array}$ \\
- la tierra prometida está más cerca de lo que puedas pensar \\
- un lugar donde brilla el sol \\
\hline
\end{tabular}

${ }^{9}$ La respuesta correcta es la 2. 


\begin{tabular}{|l}
\hline- donde está la acción \\
- ruta de calor \\
- Templo del Sol \\
- noches de luz y color \\
- tierra de pasión \\
- eterno verano al sol. \\
¿Cuáles de estas ideas se parecen a las que escribiste tú sobre la foto que has \\
visto antes?
\end{tabular}

Los estudiantes exponen sus ideas y comentan las sensaciones que les ha provocado la fotografía mostrada en el power point, así como las oraciones con las que la habían descrito. A continuación aclaramos a los discentes que la elección de la fotografía anterior ha sido capciosa y que si tantos turistas optan por ese destino ha de ser por algo. Les invitamos a que lo descubran a través de la letra de la canción. Los alumnos se distribuyen en tres grupos: dos de tres personas y uno de cuatro, se entrega a cada pequeño grupo un par de catálogos de agencias de viajes de esta zona y se les pide que realicen la actividad propuesta en la Tabla $5^{10}$

TABLA 5. Actividad proyectada en el power point

\section{LEE Y ASOCIA}

Imaginad que sois fotógrafos en una agencia de publicidad. Uno de vuestros clientes es una agencia de viajes que os ha facilitado unos eslóganes. Vuestro cometido es buscar tres fotografías que representen tres de ellos:

- Si buscas sensaciones, aquí hay algo realmente especial.

- Si quieres un paraíso, esto es lo más parecido que vas a encontrar.

- Si buscas algo que el dinero no pueda comprar... Mediterráneo.

- Mediterráneo: no hay mejor rincón en el planeta si quieres soñar.

Cuando tengan todas las fotografías, los alumnos harán tres anuncios: cada uno con una fotografía y su correspondiente eslogan, todos ellos se pegan por las paredes de la clase mientras suena de fondo la canción de Los Rebeldes. El objetivo didáctico es que conozcan un poco más la zona y que busquen imágenes que realmente puedan evidenciar la comprensión del texto ${ }^{11}$.

\footnotetext{
${ }^{10}$ El grupo de cuatro personas ha de buscar una ilustración para cada uno de los cuatro eslóganes, con lo que al final tendrán que hacer cuatro anuncios. La profesora informa a los estudiantes de que realmente pueden repartirse el trabajo y encargarse cada miembro del grupo de un eslogan.

11 Aunque por cuestiones de tiempo nosotros no llegamos a hacerlo en el aula, también se podría pedir a cada grupo que explicara por qué han seleccionado cada fotografía.
} 


\subsubsection{Actividades para trabajar la canción de Eva María}

Para trabajar con la canción de Eva María entregamos a cada alumno en papel la ficha que aparece en la Tabla 6.

TABLA 6. Ficha que la profesora entrega a los alumnos

\begin{tabular}{|c|c|}
\hline \multicolumn{2}{|c|}{ LEE, IMAGINA - CONTESTA Y COMPLETA } \\
\hline PREGUNTAS & LETRA DE LA CANCIÓN \\
\hline & $\begin{array}{l}\text { 1.Eva María se fue buscando el sol en } \\
\text { la playa }\end{array}$ \\
\hline \multirow{2}{*}{$\begin{array}{l}\text { ¿Qué época del año era? ¿Cómo } \\
\text { puede era el clima? ¿qué llevaba } \\
\text { puesto? ¿Cómo era su maleta? ¿Qué } \\
\text { había metido en ella? }\end{array}$} & 2. \\
\hline & $\begin{array}{l}\text { 3.Ella se marchó y sólo me dejó } \\
\text { recuerdos de su ausencia, sin la } \\
\text { menor indulgencia Eva María se fue. }\end{array}$ \\
\hline \multirow{2}{*}{$\begin{array}{l}\text { ¿Esperaba el narrador otra actitud } \\
\text { por parte de Eva María? ¿Qué } \\
\text { relación crees que había entre él y } \\
\text { ella? ¿Esperaba irse él con ella? ¿Por } \\
\text { qué crees que se fue sola? ¿Qué pudo } \\
\text { pasar entre los dos? }\end{array}$} & 4. \\
\hline & $\begin{array}{l}\text { 5.Paso las noches así pensando en Eva } \\
\text { María. Cuando no puedo dormir, } \\
\text { miro su fotografía. }\end{array}$ \\
\hline \multirow{2}{*}{$\begin{array}{l}\text { La fotografía se la había enviado Eva } \\
\text { María desde la playa, cómo crees que } \\
\text { era, ¿qué estaba haciendo Eva María } \\
\text { en ella? }\end{array}$} & 6. \\
\hline & $\begin{array}{l}\text { 7.¿Qué voy a hacer? ¿Qué voy a hacer? } \\
\text { ¿qué voy a hacer si Eva María se fue? } \\
\text { (x2) }\end{array}$ \\
\hline \multirow{2}{*}{$\begin{array}{l}\text { ¿Cómo es el lugar en el que estaba el } \\
\text { narrador? Qué estado de ánimo } \\
\text { tenía? ¿qué podrías sugerirle para } \\
\text { que estuviera más contento? }\end{array}$} & 8. \\
\hline & $\begin{array}{l}\text { 9. Apenas puedo vivir pensando si ella } \\
\text { me quiere, si necesita de mí o si es } \\
\text { amor lo que siente. }\end{array}$ \\
\hline
\end{tabular}


El narrador se encontró contigo y te 10. contó este problema, qué consejos le diste para que se sintiera mejor? ¿Qué le aconsejaste que hiciera respecto a Eva María?

Los alumnos han de leer la columna de la derecha y, en parejas, responder en las casillas en blanco de la derecha a las cuestiones que se plantean en la columna de la izquierda. Se trata de hacer conjeturas en algunos casos y en otros de demostrar que, sin un contexto previo, es posible también deducirlo a partir del texto o inventarlo. Con esto queremos que sean conscientes de las posibilidades narrativas que ofrecen algunas canciones, ya que ello les ayudará en la actividad final, así mismo, pretendemos que sean conscientes de algunos de los usos del Pretérito Imperfecto y del Pretérito Indefinido. Algo en lo que se incide en el momento de la puesta en común de sus respuestas.

Una vez que han realizado esta parte, se les facilita a los alumnos dos pegatinas con la información que aparece en la Tabla 7, para ello nosotros utilizamos las etiquetas que se venden en el mercado para escribir la dirección postal de los sobres. La profesora las puede hacer a mano o en el ordenador e imprimirlas después. Hacemos diez copias, una por alumno, y les decimos que las peguen en la casillas de la columna derecha que correspondan; a continuación han de escuchar la canción y completar los espacios vacios de estas dos casillas ${ }^{12}$.

TABLA 7. Casillas para imprimir en papel de pegatina

\begin{tabular}{|c|c|}
\hline \multicolumn{2}{|c|}{ PARA ESCUCHAR Y COMPLETAR } \\
\hline 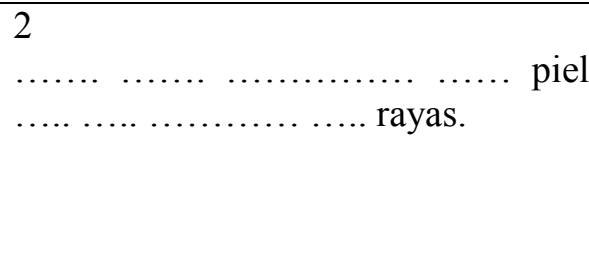 & 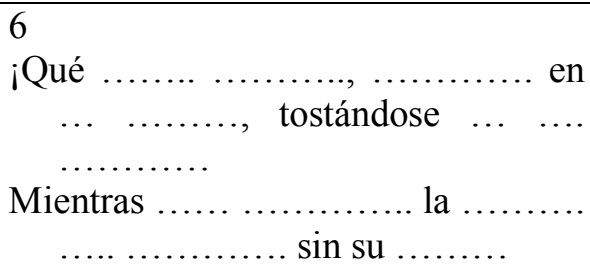 \\
\hline
\end{tabular}

3.2.3. Actividad para trabajar las canciones Vacaciones de verano y Amor de verano

Las siguientes canciones que trabajamos son las de Vacaciones de verano de Fórmula V y Amor de verano del Dúo Dinámico. Para hacer esta actividad

\footnotetext{
${ }^{12}$ La solución a la casilla 2 es: Con su maleta de piel y su biquini de rayas. La solución de la casilla 7 es: ¡Qué bonita está bañándose en el mar, tostándose en la arena! Mientras yo siento la pena de vivir sin su amor.
} 
partimos de la Tabla 8, en ella podemos ver ambas canciones fragmentadas. La actividad se realiza en parejas, por lo que la profesora imprime los fragmentos de las canciones, esto es, cada una de las celdas, cinco veces. La profesora recorta cada celda y entrega a cada pareja un juego de todas ellas. Asimismo, les dice a los estudiantes que tienen fragmentos de dos canciones: una titulada Vacaciones de verano y la otra Amor de verano. Les deja unos minutos para que los lean y les dice que va a poner la primera de las canciones. Cada pareja de alumnos ha de ir ordenando los fragmentos según los vaya escuchando. Después de la primera escuha, la profesora pone de nuevo la canción, finalmente proyecta en el power point la letra completa con el orden adecuado para que puedan corregirlo. A continuación, la profesora deja a los alumnos que intenten organizar la letra de la segunda canción. Seguidamente la profesora pone la canción para que los estudiantes comprueben sus aciertos ${ }^{13}$, después proyecta en el power point la letra original.

TABLA 8. Fragmentos de las letras de las canciones

\begin{tabular}{|c|c|}
\hline \multicolumn{2}{|c|}{ ESCUCHA, IDENTIFICA Y ORDENA } \\
\hline VACACIONES DE VERANO & AMOR DE VERANO \\
\hline $\begin{array}{l}\text { Toda mi vida ha cambiado desde } \\
\text { que te conocí. }\end{array}$ & $\begin{array}{l}\text { El final del verano llegó y tú } \\
\text { partirás. }\end{array}$ \\
\hline $\begin{array}{l}\text { Paso las noches soñando y espero } \\
\text { el momento de estar junto a ti. }\end{array}$ & $\begin{array}{l}\text { Yo no sé hasta cuándo este } \\
\text { amor recordarás. }\end{array}$ \\
\hline $\begin{array}{l}\text { Atrás se queda el invierno, la pri- } \\
\text { mavera es mejor, }\end{array}$ & $\begin{array}{l}\text { Pero sé que en mis brazos, yo te } \\
\text { tuve ayer, }\end{array}$ \\
\hline $\begin{array}{l}\text { Pronto en verano estaremos, tú y } \\
\text { yo sentiremos los rayos del sol. }\end{array}$ & $\begin{array}{l}\text { Eso sí que nunca, nunca yo lo } \\
\text { olvidaré. }\end{array}$ \\
\hline Vacaciones de verano para mí, & $\begin{array}{l}\text { Dime dime dime dime, amor, } \\
\text { dime dime que es verdad, }\end{array}$ \\
\hline Caminando por la arena junto a ti. & $\begin{array}{l}\text { Lo que sientes en tu corazón, si } \\
\text { es amor en realidad. }\end{array}$ \\
\hline Vacaciones de verano para mí. & $\begin{array}{l}\text { Nunca nunca nunca nunca más } \\
\text { sentiré tanta emoción }\end{array}$ \\
\hline Hoy mi vida comienza a despertar, & $\begin{array}{l}\text { Como cuando a ti te conocí y el } \\
\text { verano nos unió. }\end{array}$ \\
\hline $\begin{array}{l}\text { Hoy se ha abierto la puerta sin } \\
\text { llamar, }\end{array}$ & \\
\hline
\end{tabular}

${ }^{13}$ Ambas canciones son muy sencillas, por lo que no nos detenemos demasiado en ellas, pese a todo se trabaja la comprensión de parte de estas canciones en la tercera fase de la actividad. 
Hoy te tengo a mi lado y soy feliz.

\subsubsection{Actividad para trabajar la canción Un rayo de sol}

Finalmente, planteamos una sencilla actividad para trabajar con la canción $U n$ rayo de sol de Los Diablos. Les decimos a los alumnos que a veces las canciones incluyen algunas formas que no se corresponden con palabras de ninguna lengua, pero que se emplean para marcar el ritmo, en esta canción van a escuchar algunas de estas formas como shalalalala y oh, oh, oh /uooo/. Asimismo les decimos que la canción que van a escuchar es muy sencilla, por lo que entre todos vamos a intentar sacar la letra. La profesora organiza a los estudiantes en dos grupos de tres personas y dos parejas. Para trabajar la canción la divide en cuatro partes, las que aparecen en la Tabla 9 y cede el manejo del ratón del ordenador a cada pareja o grupo cada vez de forma correlativa. Cada grupo o pareja va a poder controlar el ratón en una de las partes de la canción y lo hará según las necesidades internas del grupo o pareja, de manera que puedan repetir o parar el audio si lo necesitan, pero todos los grupos o parejas deben intentar recomponer la totalidad de la letra de la canción, por lo que deben tomar nota en sus cuadernos también de las estrofas asignadas a los demás grupos o parejas ${ }^{14}$. Dentro del grupo o pareja los estudiantes se han de poner de acuerdo respecto a lo que han entendido, si no hay anuencia, pueden apuntar las diversas opciones. Una vez que todos los grupos y parejas van tomando nota de lo que vayan entendiendo de la canción, se hace una puesta en común de todas las propuestas, en el caso de que existan ambigüedades o varias respuestas, la profesora apunta todas las opciones y no da ninguna de ellas por errónea, antes bien, encuentra en esta situación una excusa más para justificar una nueva escucha de la canción. Con la segunda escucha, perfilamos bien el borrador que hemos construído entre todos, debatimos sobre las respuestas ambiguas y finalmente comparamos el borrador con la letra de la canción original que la proyectamos en el power point.

TABLA 9. Fragmentos de la letra de la canción

Un rayo de sol [oh oh oh], me trajo tu amor [oh oh oh].

Un rayo de Sol [oh oh oh], a mi corazón [oh oh oh].

Llegó de ti y me dio tu querer,

que tanto y tanto busqué y al fin tendré.

\footnotetext{
${ }^{14}$ Esta práctica, que no deja de ser una transcripción del texto oral, es al mismo tiempo una práctica habitual cuando se escucha una canción. Al ser una actividad basada en una práctica que se hace en la vida real, puede resultar más motivadora e interesante. Por otro lado, nos permite indagar en los posibles problemas que hayan podido surgir durante la escucha y que hayan obstaculizado o interferido en una correcta identificación y comprensión.
} 
Y quiero ser parte tuya, dentro de ti siempre estar, ser quien construya tu alegría y felicidad.

Seré quien vele tus sueños y daré gracias al Sol, que me hizo dueño, me hizo dueño de tu amor.

\subsection{Tercera fase: historias musicales}

La tercera fase de la actividad se destina a lo que nosotros hemos denominado historias musicales. Consta a su vez de dos partes.

\subsubsection{Primera parte: comprensión escrita y gramática}

La primera de ellas nos permite focalizar la atención en el uso de los pasados, al tiempo que, especialmente su corrección, nos invita a repasar algunos de los recursos vistos en la unidad para expresar la causa y la consecuencia o para narrar anécdotas y mostrar interés al escucharlas.

Para realizarla necesitamos el material que aparece en las Tablas 10 y $11 \mathrm{y}$, aunque es opcional, en nuestro caso para el momento de la corrección también hemos creado en la red un cuento aprovechando las herramientas que nos ofrece Internet. La Tabla $10^{15}$ incluye fragmentos de las canciones vistas anteriormente, que por tanto, no les resultan del todo ajenos a los estudiantes. La profesora imprime esos fragmentos en folios de colores, los recorta y reparte desordenados un juego de ellos a cada pareja de alumnos. La Tabla 11, por su parte, incluye un texto montado a partir de las canciones anteriores. La profesora entrega una copia de este texto a cada alumno.

Los alumnos individualmente han de completar los huecos que aparecen en la Tabla 11 con la forma verbal del tiempo en pasado que corresponda ${ }^{16}$. Dicha Tabla incluye referencias internas a otros textos que aparecen marcadas así: TEXTO. Se les explica a los alumnos que cada vez que en la Tabla 11 encuentren escrita la palabra TEXTO, han de pensar en introducir uno de los seis textos que se les ha dado. En nuestro caso, esta actividad se comenzó en el aula pero se continuó, a modo de tarea, en sus respectivas casas, de manera que los estudiantes pudieran

\footnotetext{
${ }^{15}$ Hemos incluido en este artículo la numeración, en negrita y entre paréntesis, de los textos de la Tabla 10, pero dicha numeración no se le facilita a los discentes, del mismo modo que tampoco se les facilita la información que aparece en negrita y cursiva en la Tabla 11, pues, de lo contrario les daríamos resuelta la actividad.

${ }^{16}$ Pese a que ésta no deja de ser la típica actividad de completar huecos, ello no significa que no sea útil, además hemos pretendido darle otra apariencia con la inclusión de la música y las nuevas tecnologías en la corrección. Por otro lado, la actividad no finaliza al completar los huecos, se evalúa la comprensión lectora a través de la inclusión de los textos de las canciones. Al mismo tiempo esta primera parte de completar huecos, tan guiada y de respuesta cerrada, sirve de "entrenamiento" para la segunda parte, mucho más abierta por cuanto es de respuesta libre.
} 
dedicarle todo el tiempo que precisaran si así lo querían. Fue interesante comprobar al día siguiente cómo muchos de los estudiantes se habían unido en parejas para hacer toda la actividad.

TABLA 10. Fragmentos de canciones con los que completar el texto de la Tabla 11

Mediterráneo, ruta de calor./ Mediterráneo, al Templo del Sol.

Mediterráneo, noches de luz y color./ Mediterráneo, tierra de pasión.

Mediterráneo, ruta de calor./ Mediterráneo, eterno verano al sol.

\section{(Texto 1)}

Si buscas sensaciones, aquí hay algo realmente especial.

Si quieres un paraíso, esto es lo más parecido que vas a encontrar.

Si buscas algo que el dinero no pueda comprar

y si quieres ver a mescalina nadar.

No hay mejor rincón en el planeta, si quieres soñar.

\section{(Texto 2)}

Eva María se fue, buscando el sol en la playa, con su maleta de piel y su bikini de rayas.

Ella se marchó y solo me dejó recuerdos de su ausencia.

Sin la menor indulgencia, Eva María se fue.

\section{(Texto 3)}

Vacaciones de verano para mí, caminando por la arena junto a ti.

Vacaciones de verano para mí.

Hoy mi vida comienza a despertar, hoy se ha abierto la puerta sin llamar, hoy te tengo a mi lado y soy feliz.

(Texto 4)

El final del verano llegó y tú partirás.

Yo no sé hasta cuándo este amor recordarás.

Pero sé que en mis brazos, yo te tuve ayer, eso sí que nunca, nunca yo lo olvidaré.

(Texto 5)

Dime dime dime dime, amor, dime dime que es verdad, lo que sientes en tu corazón, si es amor en realidad. 
TABLA 11. Texto entregado para trabajar con los tiempos del pasado

Pon el verbo en la forma del pasado que corresponda:

Eva María (ser) ........... una mujer de 28 años, agradable, hermosa y con una situación laboral y amorosa estable. Durante el año (trabajar)........... y (trabajar) ......... sin parar y (tener) ............la sensación de que lo único que (hacer).............. en su vida hasta ese momento (ser) ....... trabajar.

Como (ver) ...... que su juventud (acabarse)....... y (pensar)..... que su vida (ser)........ demasiado aburrida, (decidir)......... cambiar su historia. De manera que (pensar) ........ hacer un viaje.

Una amiga le (decir)........... que el año anterior (hacer) un viaje inolvidable y que si (querer) ...............le (poder).............. llevar los folletos que (conservar)............... aún de él. Su amiga le (llevar)......... los folletos a casa, en ellos (poner)

\section{TEXTO (Respuesta: Texto 1)}

Pero, aquel (parecer) un lugar demasiado aventurero para Eva María, así que, para asegurarse de que su decisión (ser)..... la correcta, Eva María (irse)......... a una agencia de viajes. Allí, la dependienta le (decir)...... TEXTO (Respuesta: Texto

En aquel momento, Eva María (pensar) ............ que eso era lo que realmente (estar) .............. buscando y que, para disfrutarlo al máximo, (tener)......... que hacer aquel viaje sola. Ella siempre (viajar) ........... con su novio Julián o con sus padres y, aunque aquellos viajes le (servir)........... para descansar y relajarse, ese año ella (querer) .......... más acción. De modo que (llegar) ........ a su casa, (hacer) .......... la maleta, (escribir) ............ una nota a Julián y (marcharse) ............

Cuando Julián (regresar) .......... a casa del trabajo, (encontrar) .......... la nota que le (escribir) .............. Eva María. Como últimamente no (estar).......... muy cariñoso con ella, Julián (pensar) .......... que aquella actitud de Eva María (significar).......... solo una cosa: ella (querer) .......... dejar la relación. Al día siguiente Julián (seguir)....... sintiéndose muy triste, así que, sin dudarlo un instante, (llamar) ........... a su mejor amigo y le (contar)...... lo que (pasar)..............: TEXTO (Respuesta: Texto 3)

$\mathrm{Su}$ amigo le (aconsejar) ......... que hiciera lo posible para ir con ella. Julián (ver) ....... en su casa los folletos de la amiga de Eva María y, en aquel momento, (saber) ....... dónde (estar) ........ Eva María.

Mientras tanto, Eva María (llegar)..... a su Hotel, (ser)........ precioso, (tener) ....... vistas al mar, (hacer) ........ muy buen tiempo y además (estar) ........ muy contenta, porque en el viaje (conocer) ......... a Paco, un chico de esa ciudad que (ofrecerse)......... para enseñarle los lugares más turísticos de la zona. Pese a que Paco(ser) ........ encantador, Eva María (empezar).......... a echar de menos a Julián. Sin embargo, aquel día, al subir a la habitación del hotel, (encontrarse) ...... 
la puerta abierta. Al principio Eva María (asustarse) ....... mucho, pero después (descubrir) ....... que tras la puerta le (esperar)........ una gran sorpresa, Julián (ir). hasta allí para estar con ella.

A la mañana siguiente, Eva María y Julián (decidir)....... ir a la playa, por el camino, Eva María (cantar): TEXTO (Respuesta: Texto 4)

Paco (ver)..... a Eva María y a Julián juntos y (consolarse).......... pensando: TEXTO (Respuesta: Texto 5)

Julián, por su parte, no (poder) ........ evitar preguntar a Eva María: $\underline{\text { TEXTO }}$ (Respuesta: Texto 6)

Eva María (sentirse)....... muy feliz, (darse) ......... cuenta de que lo más importante no (ser) ...... el trabajo, sino el amor. Aquel viaje (servirle)........... para comprobar que realmente Julián (ser) ......... el hombre de su vida.

Para corregir la actividad la profesora crea un cuento con este material en la página web de StoryJumper. El enlace que nos remite a este material es el siguiente: http://www.storyjumper.com/book/index/6719982/Melodía-de-verano. Como se puede ver en él, las formas verbales que los alumnos debían completar aparecen resaltadas en el texto en otro color y tamaño mayor, además, los bocadillos de los personajes invitan a reflexionar sobre el uso de ciertas expresiones como de modo que, de manera que, así que, etc. y muestran de forma contextualizada algunos de los recursos que se han visto en clase para contar anécdotas y mostrar interés al escucharlas.

Antes de la corrección, la profesora localiza en youtube los enlaces de las canciones que se insertan en el texto del cuento y en los minutos que se dicen en él, para tenerlos preparados. Estos enlaces remiten a los cortes de las canciones de la Tabla 10. Así, en el momento de la corrección, se baja la intensidad de las luces (sin llegar a la obscuridad, pues los estudiantes han de corregir sus textos) y se proyecta el cuento con ayuda de un cañón, la profesora va leyendo en voz alta y cada vez que haya en el texto un enlace a una canción, la profesora hace que suene el corte adecuado. El resultado final es una historia mezclada con fragmentos sonoros de canciones.

\subsubsection{Segunda parte: expresión escrita}

Una vez que ya hemos trabajado las canciones, hemos reflexionado sobre los usos del pasado y hemos proporcionado a los alumnos una historia con todas las canciones a modo de muestra por la que poder guiarse, les pedimos a los estudiantes que hagan algo similar, esto es, que escriban una anéctoda o narración en pasado en la que inserten partes de canciones.

Como éramos conscientes de la dificultad que una tarea tal podía entrañar, puesto que lo habíamos hecho también nosotros anteriormente, les dejamos a los alumnos cinco días para que lo prepararan, les aclaramos que podían incluir canciones en su lengua materna, pues el repertorio de canciones entre el cual 
podían elegir fragmentos que encajaran con sus textos era mayor, y les dimos la opción de hacerlo en grupos de tres personas, parejas o individualmente, ya que un trabajo así implica no sólo un cierto dominio de la lengua española, sino también un cierto grado de análisis de las posibilidades que ofrecen las canciones y de creatividad para inventar el texto de la historia y asociarlo de forma coherente a la letra de las canciones.

Mostramos seguidamente, a modo de ejemplo, el texto corregido de uno de los alumnos:

TABLA 12. Ejemplo de texto escrito por un alumno ${ }^{17}$

Aquí estaba en el jardín. Era perfecta: una buena personalidad, tranquila, pero llena de energía, una sonrisa perfecta y al final erábamos vecinos. La había conocido por mucho tiempo antes de darme cuenta [de] que asistía [a] la misma universidad. A veces nos ve[í] más sucedía que un[a] inclinación de cabeza, como si dijera que sé que tú existes. Entonces, una noche, tuve un sueño muy lúcido. Contiene ella y yo [En el que aparecíamos ella y yo]. Quería hablarla[le] de él, quería decir:

Last night I had a dream about you./ In this dream, I'm dancing right beside you. And it looked like everyone was having fun./The kind of feeling I've waited so long.

Don't stop, come a little closer,/ as we jam, the rhythm gets stronger. There's nothing wrong with just a little, little fun/ We were dancing all night long

The time is right to put my arms around you.

You are feeling right, you wrap your arms around too.

But suddenly I feel the shining sun,/ before I knew it, this dream was all gone.

Decidí a eso [en ese] momento pedirla[pedirle] si quería salir conmigo. No era [estaba] seguro [de] cuándo iba a pedirla [pedírselo], pero la primera oportunidad se presentó et [al] lunes siguiente en el mercado. Hemos comprado en [Normalmente comprábamos] el mismo día por mucho tiempo, pero el lunes fue una ocasión muy rara. Por [Como] mis amigos habían comido mi comida durante

${ }^{17}$ En el texto aparecen ciertas palabras sombreadas y subrayadas, se corresponden con las correcciones que hizo la profesora. Se acordó desde el principio del curso que cada escrito de los alumnos que se fuera a tener en cuenta para la evaluación, se entregaría a la profesora, ésta, a su vez, señalaría las partes erróneas ofreciendo cuanta información fuera pertinente para que los discentes pudieran corregir sus textos, una vez que los corrigieran, debían entregarlo nuevamente a la profesora que finalmente calibraba tanto el texto como las correcciones. Se optó por este método, pues nos parece que puede hacer más consciente al alumnado de sus errores y, en la medida que así sea, puede tratar de solventarlos. Así mismo, hemos incluido aquí, entre corchetes, la opción que consideramos más acertada. 
el partido, el sábado pasado tenía [tuve] que comprar más comida pronto. Estaba caminando por la tienda, cuando de repente apareció ella. [La] Miré a ella y ella [me] miró a mí, sin pensar le dije a ella:

It might not be the right time,/ I might not be the right one.

But there's something about us I want to say

Because there's something between us anyway

I might not be the right one/ It might not be the right time

But there's something about us I've got to do/ Some kind of secret I will share with you

I need you more than anything in my life,/ I want you more than anything in my life

I'll miss you more than anyone in my life/ I love you more than anyone in my life.

Me sorprendió que me respondiera en [de] una manera muy [tan] positiva.iQué chulo!

Nuestra primera cita fue el [al] siguiente viernes. Todo era perfecto: la elección del restaurante, el tipo de comida, el coche, los [las] flores..., todo. ¡Estaba tan emocionado...! Llegué a su casa temprano por [con] cinco minutos [de antelación] y tenía los [las] flores en la mano. Cuando abría la puerta, le di a ella los [las] flores. Estornudó. Era alérgica a esto [este] tipo de flor..., pero después de este problema (muy pequeño) continuamos [camino] al restaurante. No sabía que la mala suerte no terminaba [había terminado]. En mi entusiasmo de este [esta] noche, se me había olvidado llenar el coche con gasolina . [A] un kilómetro del restaurante, el coche paró. Ella me miró y si [las] mirada[s] mataría [mataran/matasen]...Después de empujarlo a la gasolinera, llené el coche con gasolina, de repente me di cuenta [de] que no tenía la cartera. ¡Ay! ¿Por qué? Afortunadamente ella podía [pudo] pagar por mí. Finalmente llegamos al restaurante sin otro problema.

Nos acercamos el [al] camarero y nos dijo [pidió] el nombre de la reservación. Se lo di. Había [Hubo] un[a] pausa. "Discúlpeme, señor" me dijo, "pero el nombre no está en la lista", “¿En serio?” "Sí, señor” “¿Tienes una mesa disponible para dos?" No, señor, estamos 1leno[s] esta noche".

Con estas palabras, ella tomó las llaves de mi mano y se fue en el coche. Suspiré con exceso [profundamente]. Salí [d]el restaurante para encontrar un teléfono público. Mientras tanto me pensaba:

I'm at a payphone trying to call home /All of my change I spent on you Where has the time gone, baby, it's all wrong/ Where are these plans we made for two 
Regresé a mi casa ... en [a] pie. [A] La mañana siguiente, mi coche apareció delante de la casa, las llaves estaba[n] en el buzón. Sentaba [Yo estaba sentado] en el porche, cuando un coche se condució a [condujo hasta] a la casa [de] en frente de la mía, contenía muchas cajas. Una mujer salí[ó] [d]el coche. ¡Qué belleza! Rápidamente encontré un lápiz y hoja de papel. Escribí mi número de teléfono y corre [corrí] a su casa. Sin introducirme [presentarme], se [le] di el papel diciendo:

Hey I just met you and this is crazy, but here's my number, so call me, maybe?

\section{John Coolidge}

La lectura de los textos de los alumnos se hizo de la siguiente manera: un grupo se levantaba y, en el ordenador de la clase, preparaba los enlaces de las canciones y los cortes que iba a necesitar (generalmente para esta búsqueda acudieron a youtube) y mientras lo hacía, la profesora y el resto de alumnos corregían alguno de los ejercicios que habíamos mandado de tarea el día anterior. Cuando cada grupo estaba listo, cesábamos la corrección de la tarea y escuchábamos la lectura que nos proponían. Como curiosidad diremos que dicha lectura despertó el interés de los alumnos, el cual aumentó cuando éstos vieron que en varios cuentos los protagonistas eran los propios alumnos del mismo grupo o de otros grupos.

\section{CONCLUSIONES}

Las canciones son un material versátil que permite trabajar todos los contenidos lingüísticos, pragmáticos y sociolingüísticos de la lengua meta, contribuyendo al desarrollo de la competencia comunicativa de los alumnos en dicha lengua. En el trabajo con las canciones que se incluye en la propuesta que hemos hecho, se puede observar cómo a través de ellas se pueden proponer actividades de lengua orales y escritas, si bien, dado que en la teoría nos hemos centrado más en la comprensión oral, en la práctica hemos querido también incidir en el desarrollo de esta destreza (segunda fase de la propuesta didáctica), de ahí que hayamos prestado especial atención a la progresión en cuanto a la exigencia de las tareas de escucha. De esta manera se comienza con actividades en las que se pide la identificación de un tema o de unas palabras y se acaba con una actividad de transcripción. Esta cuidada progresión permite que el alumnado con mayores dificultades en comprensión oral no se pierda durante el transcurso de la clase, perciba la actividad como asequible, pueda ir evaluando sus propios avances y sea consciente de sus dificultades para atajarlas mediante la puesta en marcha de estrategias de escucha, que en varias ocasiones están implícitas en el propio planteamiento de la actividad. Así mismo, se han incluido actividades de escucha con objetivos diversos, para no incurrir en la monotonía y dar opciones a que los alumnos pudieran, una vez más, ser conscientes de sus puntos fuertes y débiles en este sentido. 


\section{BIBLIOGRAFÍA}

BALLESTEROS EGEA, M. (2009): "La didáctica de las canciones en inglés desde una metodología musical y de la lengua inglesa" en Ensayos. Revista de la Facultad de Educación de Albacete 24, 123-132, [en línea]. Disponible en la web: http://www.uclm.es/ab/educacion/ensayos/ensayos24/pdf/24_10.pdf. [Consulta: 3 de febrero de 2013]

BARALO OTONELLO, M. (1999): La adquisición del español como lengua extranjera, Madrid, Arco Libros.

CONSEJO DE EUROPA (2002): Marco Común Europeo de Referencia para las lenguas:Aprendizaje, Enseñanza, Evaluación, Madrid, Anaya. [En línea] Disponible en la web: http://cvc.cervantes.es/ensenanza/biblioteca_ele/marco/ cve mer.pdf [Consulta: 3 de febrero de 2013].

JIMÉNEZ, J.F. MARTÍN y PUIGDEVALL (2009): “Tipología de explotaciones didácticas de las canciones" en Monográficos MarcoEle, 9, 129-140, [en línea]. Disponible en la web http://marcoele.com/descargas/expolingua_1999.jimenezmartin-puigdevall.pdf. [Consulta: 3 de febrero de 2013].

LLORENTE, L.I. (2009): "El ritmo de la gramática: la música en la clase de Español como Lengua Extranjera (E/LE)", en Cauce. Revista internacional de Filología, Comunicación y sus Didácticas, 32, 69-81, [en línea]. Disponible en la web: http://cvc.cervantes.es/literatura/cauce/pdf/cauce32-33/cauce_32-33_ 008.pdf [Consulta: 3 de febrero de 2013].

MALEY, A. (1987): "Poetry and song as effective language- learning activities". En Rivers, W. (ed.): Interactive Language Teaching, Cambridge, CUP.

MURPHEY, T. (2010): Music \& song, China, Oxford University Press.

NARANJO PITA, María (1999): La poesía como instrumento didáctico en el aula de ELE: memoria final máster en formación de profesores especialistas en la enseñanza de ELE, Madrid, Edinumen.

PRADO MARTÍN PRADO, M. del (2004): "La explotación didáctica de las canciones en el aula de italiano como lengua extranjera", en Lenguaje y textos, 22, 41-48, [en línea] . Disponible en la web: http://ruc.udc.es/dspace/ bitstream/2183/8229/1/LYT_22_2004_art_4.pdf [Consulta: 3 de febrero de 2013]

SANTOS GARGALLO, I. (1999): Lingüística aplicada a la enseñanza aprendizaje del español como lengua extranjera, Madrid, Arco Libros.

RODRÍGUEZ LÓPEZ, B. (2005): "Las canciones en la clase de español como lengua Extranjera" En Álvarez, A. et alter (eds.): Actas del XVI Congreso Internacional de ASELE. La competencia pragmática o la enseñanza del español como lengua extranjera, Oviedo, Servicio de Publicaciones de la Universidad de Oviedo, 806-816. Disponible en la web: http://cvc.cervantes.es/ ensenanza/biblioteca_ele/asele/pdf/16/16_0804.pdf [Consulta: 3 de febrero de 2013] 
UR, P. (1997): A course in language teaching, Cambridge, Cambridge University Press.

WHITE, G. (2003): Resource books for teachers: Listening, Hong Kong, Oxford University Press.

http://www.storyjumper.com/book/index/6719982/Melodía-de-verano Enlace a la historia en formato cuento para la corrección. [Consulta: 3 de febrero de 2013] http://www.youtube.com/watch?v=1Hn3PSvU0ic Enlace a la canción Mediterráneo de Los Rebeldes. [Consulta: 3 de febrero de 2013]

http://www.youtube.com/watch?v=ELnkgb228Pk Enlace a la canción Eva María de Fórmula V. [Consulta: 3 de febrero de 2013]

http://www.youtube.com/watch?v=1-gykC6d3Go Enlace a la canción Vacaciones de verano de Fórmula V. [Consulta: 3 de febrero de 2013]

http://www.youtube.com/watch?v=MRR-zI6GdEc Enlace a la canción El final del verano del Dúo dinámico [Consulta: 3 de febrero de 2013]

http://www.youtube.com/watch? $\mathrm{v}=\mathrm{nXCVkGvFo} 4 \mathrm{Y}$ Enlace a la canción Un rayo de sol de Los diablos. [Consulta: 3 de febrero de 2013] 